\title{
Pulmonary arterial hypertension associated with schistosomiasis
}

INSERM

\section{Source}

INSERM. (1999). Orphanet: an online rare disease and orphan drug data base. Pulmonary arterial hypertension associated with schistosomiasis. ORPHA:275823

Pulmonary arterial hypertension associated with schistosomiasis (PAHS) is a form of pulmonary arterial hypertension (see this term) characterized by an elevated pulmonary arterial resistance leading to right heart failure, observed as a complication of a chronic schistosomiasis (see this term). 